\title{
La novela Mercedes, de Marco Antonio Jaramillo
}

Marco Antonio Jaramillo vivió en los años de 1849-1904. Nacido en Sonsón, parece haber pasado la mayor parte, si no es que toda su vida, en esa ciudad de la provincia colombiana de Antioquia. Su única obra de ficción publicada, es una novela. Este relato ha recibido comentarios muy favorables. Agustín del Saz, en su reciente copilación sobre la novela hispanoamericana, ${ }^{1}$ se refiere a Mercedes, como "la celebradísima novela". El padre Ortega Torres la elogia recordando que Tomás Carrasquilla la llamó la mejor novela colombiana después de María. ${ }^{2}$

Después de haber leído Mercedes, me han puesto perplejo los comentarios altamente encomiásticos de estos críticos respetables. Sorprende especialmente que Tomás Carrasquilla, uno de los más distinguidos novelistas de su país, haya elogiado esta novela de tal modo. ${ }^{3}$ Para mi, Mercedes es bastante inferior, y excepto para aquellos interesados en la historia de la novela colombiana, realmente merece el olvido relativo en que se halla.

Los ejemplares de Mercedes son ahora muy difíciles de encontrar. Gracias a la inusitada generosidad del doctor Bernardo Toro, de Medellín, un ejemplar de este raro volumen vino a parar recientemente a mis manos. Consta de 302 páginas bastante pequeñas. En la cubierta, aparte del nombre del autor, título, lugar y fecha de publicación (Medellín, 1907), se lee: "Sonsón, mayo de 1900". Como Jaramillo murió en 1904 y su libro fué publicado póstumamente, tres años más tarde, "Sonsón, mayo de 1900" debe significar el lugar de composición y el mes y año en que fué terminada. 
El padre Ortega Torres considera a Mercedes como "novela de carácter histórico", y así es. Sin embargo, más que de la historia política de este período (la revolución de 1860 y los sucesos de años anteriores y posteriores a ese desastre), la novela trata de las vidas de ciertos personajes que habitan en Sonsón y alrededor de ese lugar, y estos individuos aparentemente tienen realidad histórica. En un interesante preámbulo a la novela, dedicado a sus hijas, Jaramillo les ofrece este relato verdadero. No es realmente una novela, especifica él; hasta entonces les ha prohibido leer novelas porque "esos libros, por inocentes que parezcan, engañan a las jóvenes, pintándoles una vida que no es la vida real", y espera que gocen estudiando "la humana vida" en su libro. También hay un epílogo a la novela, en el cual aclara que Mercedes era un ser viviente, una buena amiga. Su libro, pues, describe la tragedia que destruyó la vida de una persona que él conoció bien. Cuán exactamente reales sean los otros personajes no: se puede asegurar; pero se presume que al menos tienen algo de realismo. En tres ocasiones Jaramillo ofrece notas que comprueban la verdad de los incidentes que narra, y uno de ellos atañe a Antonio Hurtado, el protagonista de la novela. Es posible que Jaramillo haya disfrazado sus personajes por medio de nombres ficticios.

La trama de Mercedes es bastante sencilla. Antonio, hijo de don Pedro, se educa en Sonsón y también en el cercano rancho paterno. A otro miembro de la familia, su prima Mercedes, más joven que él, la acogieron en el seno de la familia cuando su madre murió. De niño, Antonio muestra una disposición demasiado agresiva, tendencia a disputas y a crear conflictos; unido a su agresividad, hay un temperamento violento que no puede reprimir. Es muy inteligente; sobresale en la escuela y parece tener un brillante futuro. Mercedes, a los 14 años, florece como una hermosa mujer y Antonio comienza a amarla apasionadamente. Ella corresponde a su afecto, pero muy castamente, y cuando a los 18 años él quiere interrumpir sus estudios en la Universidad de Medellín y casarse, ella insiste con sus padres para que regrese por un año más. Así se hace.

Como el día fijado para el regreso de Antonio se aproxima, los jóvenes enamorados están muy impacientes por reunirse; la boda se hará en plazo corto. Don Pedro en ese día infortunado, cabalga para encontrar un caballo que se le ha perdido; después de hallarlo; 
don Pedro busca refugio bajo un árbol, donde ambos, hombre y bestia, caen muertos por un rayo. Antonio al ir a casa apresurándose por la tormenta, ve el cuerpo de su padre muerto; el terrible golpe lo vuelve loco. Cuando Mercedes y su madre lo encuentran, no las reconoce y tiene que ser contenido por la fuerza, por los sirvientes, para prevenir actos de violencia.

La locura de Antonio es por mucho tiempo incurable en apariencia, aunque el doctor de la familia espera una posible recuperación, por medio de alguna emoción súbita. Los años pasan, y Antonio vive cuidado por su madre, amorosa y afligida, y la fiel Mercedes. $\mathrm{Su}$ amor no decrece nunca, y cuando un joven y brillante médico, que visita al doctor de la familia, viene a examinar a Antonio y se enamora de ella, rehusa su oferta matrimonial, sin la menor vacilación. Vive con la firme esperanza de la recuperación de Antonio. $Y$ ésta llega a través de una serie de sucesos culminantes que no necesitan recapitularse en este breve sumario. Pero la recuperación es únicamente un preludio a su decisión de unirse al ejército conservador y ayudar a derrotar a los liberales, quienes en la guerra civil de 1860 están asolando el país. (La simpatía de Jaramillo por la causa conservadora es una de las más positivas características de su libro.)

Antonio muere en un combate. Ha dejado toda su hacienda a Mercedes, pues su madre murió poco antes. Mercedes vive en la casa familiar, en Sonsón, hasta que la ataca el cáncer, cercana a los cuarenta años.

El paralelo entre Mercedes y María resulta obvio. Ambas pintan la tragedia de un amor de jóvenes frustrado por la muerte. La locura de Antonio tiene paralelo en la epilepsia de María. Ambas se sitúan en la Colombia rural y ofrecen gran riqueza de costumbres. La concepción del tema tanto de Isaacs como de Jaramillo, es valiosa; es en la ejecución del tema en donde Jaramillo se muestra deficiente. Mientras Isaacs, con arte singular, desarrolla su tema principal, sin permitir la intrusión de asuntos extraños de importancia, Jaramillo, incapaz de mantener la unidad de su relato, no puede manejar bien el factor más importante en su trama. Como consecuencia de ello, desvía su atención frecuentemente hacia otros personajes o incidentes, con tal insistencia que el lector se halla perdido, pues no sabe cuáles son los caracteres principales y cuál se supone 
que sea el tema principal. Estos cambios son, a menudo, desconcertantemente abruptos; la técnica de transición del autor, al pasar de un incidente a otro, es muy rudimentaria. Puede dar la medida de su falta de capacidad para comprender la técnica de construcción de la trama; el hecho de que aun haya intitulado mal su novela, como la misma Mercedes se lo señala en el epílogo. Realmente debiera de haberse llamado Antonio (o, como sugiere Mercedes, quizás La venda roja, referencia a la cinta roja que, según dice Antonio, desciende sobre sus ojos durante sus ataques de locura total). Con terquedad dictada por su afecto hacia ella, Jaramillo rehusa a Mercedes cambiar el nombre de su novela, y el resultado es un relato en el cual al personaje del título se le concede sólo un espacio menor. Unicamente cuando se termina de leer la novela, se puede decidir lo que Jaramillo pretendía en su historia.

La pintura de costumbres de Jaramillo es espléndida y aquellos pasajes en que trata de ellas son excelentes. Su diálogo es a menudo vivaz y verosímil ; su reproducción del lenguaje rural de esa región es auténtico. $\mathrm{Su}$ capacidad para crear y pintar caracteres, sin embargo, es mucho menos segura. Como el requisito principal de una novela que pretende ser real, es la creación de personajes convincentes, encontramos difícil perdonar esta falta a Jaramillo. E1 Antonio de Jaramillo no tiene completo sentido, dentro o fuera de su locura; es menos que humano. En las páginas dedicadas a la niñez de Antonio, no dibuja su carácter claramente, y no sabe uno a qué atenerse en cuanto a su manera de ser, o a lo que de él debe pensarse. Parece, a veces, que es un pequeño monstruo. Cuando crece, se vuelve casi un ejemplo de virtud, y este aparente cambio de carácter no es, por muchos motivos, lo bastante convincente. Pero en la explicación de la locura de Antonio es donde uno se encuentra desconcertado: en ninguna parte de su novela el autor ha ambientado al lector adecuadamente para este súbito ataque, y por algún tiempo es casi increíble. Se expone, después, que el carácter de Antonio cuando niño ya llevaba el germen de su locura posterior; que sus ataques de rabia incontrolable rayaban realmente en locura. Esto -es en verdad posible; pero hasta el momento de su impulso inicial, estamos totalmente impreparados para ello. Similarmente, el suicidio de dos de los mejores amigos de Antonio al principio de la his- 
toria, lo motiva y explica de manera muy pobre, y aunque Jarami110 asegura que el episodio es verdadero, no quedamos satisfechos.

Ei carácter de Mercedes, a lo que parece, es admirable. Ella es, en verdad, semejante a María, la heroína de Isaacs; pero la creación de Jaramillo no está plenamente lograda; no es en realidad una persona, en suma, la que Jaramillo recrea. Modelo de belleza femenina y de virtud, es realmente demasiado buena para este mundo, y la advertencia de Jaramillo a sus hijas, en el preámbulo de este relato: que deben guardarse de la ficción pues sus personajes no son reales, parece tener aplicación a su propia novela.

Debe uno desgraciadamente concluir, por ello, que Mercedes ha sido demasiado bien calificada, y que al compararla favorablemente con Maria o con cualquier otra de las mejores novelas colombianas, se le hace un inmerecido favor. Jaramillo no entendía realmente la personalidad humana, o no podía, al menos, retratarla de una manera convincente. Hay partes de su novela que son desconcertantemente pueriles. $\mathrm{El}$ padre Ortega Torres, en las páginas anteriormente citadas, dice de Jaramillo: "Es autor importante, pero poco conocido." No es injusto sugerir que la importancia de Jaramillo para la novela colombiana, es realmente bastante menor y que su fracaso, en cuanto a que no se le recuerde ni lea hoy en día, es en gran parte merecido.

Gerald E. Wade, The University of Tennessee.

\section{$\mathrm{N} O \mathrm{TAS}$}

1 Agustín del Saz, Resumen de historia de la novela hispanoamericana. Barcelona, 1949, p. 211.

2 José J. Ortega Torres, Historia de la literatura colombiana. $2^{2}$ ed. Bogotá, 1935, p. 508. No he encontrado ninguna otra referencia a Mercedes en los volúmenes usuales sobre literatura colombiana.

3 E1 juicio de Carrasquilla acerca de otras figuras literarias de su tiempo es igualmente pasmoso; ver Rafael Maya, "Las 'Homilias' de Carrasquilla", Bolivar, núm. 14, pp. 759-761. En el caso de Jaramillo, Carrasquilla probablemente fté engañado por la excesiva generosidad hacia un antioqueño paisano styo, y también por su entusiasmo por la aproximación realista de Jaramillo a la literatura. Esta cercanía era poco común y carecía de popula- 
ridad en Colombia, en la época de Mercedes y su aparición; se prefería el modernismo y las extravagancias literarias, mientras la actitud de Carrasquilla (y Jaramillo) hacia su arte, era muy avanzada para su época. Para la opinión de Carrasquilla sobre la literatura de su tiempo, ver "Homilías", en Bolivar, número de referencia, pp. 763-79.5. 